Supporting Information for

\title{
Direct electrochemical pathways for selenium reduction in aqueous solutions
}

\author{
Shiqiang Zou and Meagan S. Mauter ${ }^{*}$ \\ Department of Civil and Environmental Engineering, Stanford University, Stanford, \\ California 94305, United States
}

${ }^{*}$ Corresponding author.

Meagan S. Mauter. Phone: (650) 725-4911; e-mail: mauter@stanford.edu

Total pages: 8 excluding cover page

Total Figures: 11

Total Equations: 11 


\section{Setup of the three-electrode electrochemical system}

To remove surface contaminants and impurities from the Au foil, each sample was soaked in $1 \mathrm{M} \mathrm{HCl}$ for 60 minutes, rinsed with Milli-Q water, soaked in ethanol for 60 minutes, sonicated in Milli-Q water for 15 minutes, and air-dried in a fume hood overnight. The reference and counter electrodes were thoroughly cleaned in Milli-Q water before each use. The electrochemical cell was covered by a customized 3-D printed lid with four holes for the working electrode, reference electrode, counter electrode, and a temperature sensor (Fig. S1).
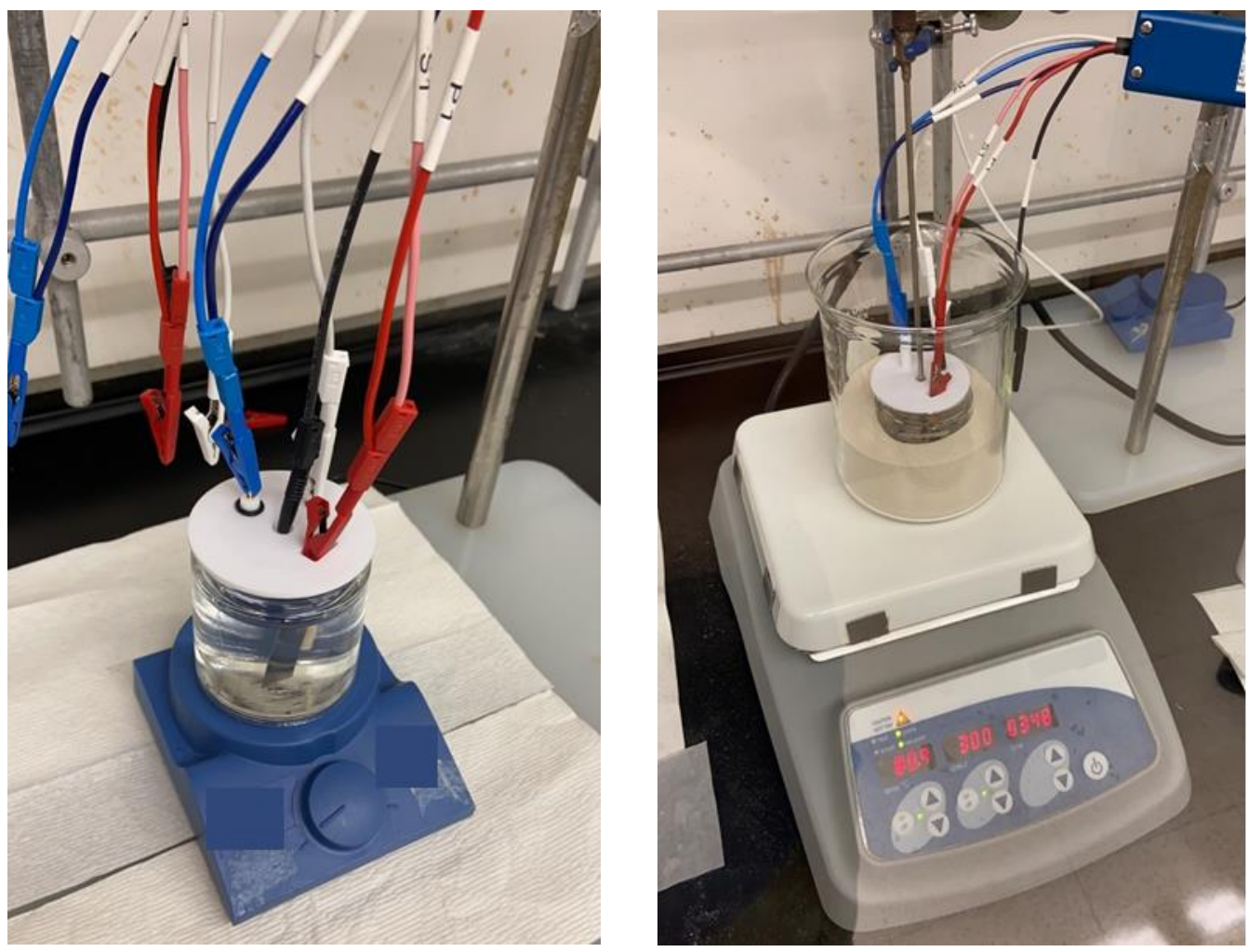

Figure S1. Setup of the three-electrode electrochemical system for room temperature operation (left) and high temperature operation (right).

\section{Quantification of performance metrics}

The Se removal efficiency $(E, \%)$ was quantified as

$$
E=\frac{C_{i} \times V_{i}-C_{f} \times V_{f}}{C_{i} \times V_{i}} \times 100 \%
$$

where $C_{i}$ and $C_{f}\left(\mathrm{mg} \mathrm{L}^{-1}\right)$ are the initial and final Se concentration in the water matrix, and $V_{i}$ and $V_{f}(\mathrm{~L})$ are the initial and final solution volume. Similarly, the Se removal rate $\left(R, \mathrm{mg} \mathrm{m}^{-2} \mathrm{~h}^{-1}\right)$ was estimated as

$$
\mathrm{R}=\frac{\mathrm{C}_{\mathrm{i}} \times \mathrm{V}_{\mathrm{i}}-\mathrm{C}_{\mathrm{f}} \times \mathrm{V}_{\mathrm{f}}}{\mathrm{A} \times \mathrm{t}} \times \frac{3600 \mathrm{~s}}{\mathrm{~h}}
$$


where $t(\mathrm{~s})$ is the operation time. The theoretical Se deposition capacity ( $D_{\text {theorectical }}, \mathrm{mg}$ $\mathrm{m}^{-2}$ ) or the observed Se deposition capacity $\left(D_{\text {observed }}, \mathrm{mg} \mathrm{m}^{-2}\right)$ was determined by

$$
\begin{array}{r}
\mathrm{D}_{\text {theorectical }}=\frac{\Sigma(\mathrm{I} \times \mathrm{t})}{\mathrm{n} \times \mathrm{F} \times \mathrm{A}} \\
\mathrm{D}_{\text {observed }}=\frac{\mathrm{C}_{\mathrm{i}} \times \mathrm{V}_{\mathrm{i}}-\mathrm{C}_{\mathrm{f}} \times \mathrm{V}_{\mathrm{f}}}{\mathrm{A}}
\end{array}
$$

where $I(\mathrm{~A})$ and $t(\mathrm{~s})$ are the current and time profiles recorded by potentiostat, $n$ ( 4 or $6)$ is determined by Se reduction pathway, $F$ is Faraday constant $\left(96485 \mathrm{C} \mathrm{mol}^{-1}\right)$, and $A$ is the effective electrode area $\left(\mathrm{m}^{2}\right)$. We also quantified the Faradaic efficiency $(F, \%)$ of SeDER by

$$
\mathrm{F}=\frac{\mathrm{D}_{\text {observed }}}{\mathrm{D}_{\text {theoretical }}} \times 100 \%
$$

\section{Surface morphology and elemental mapping}
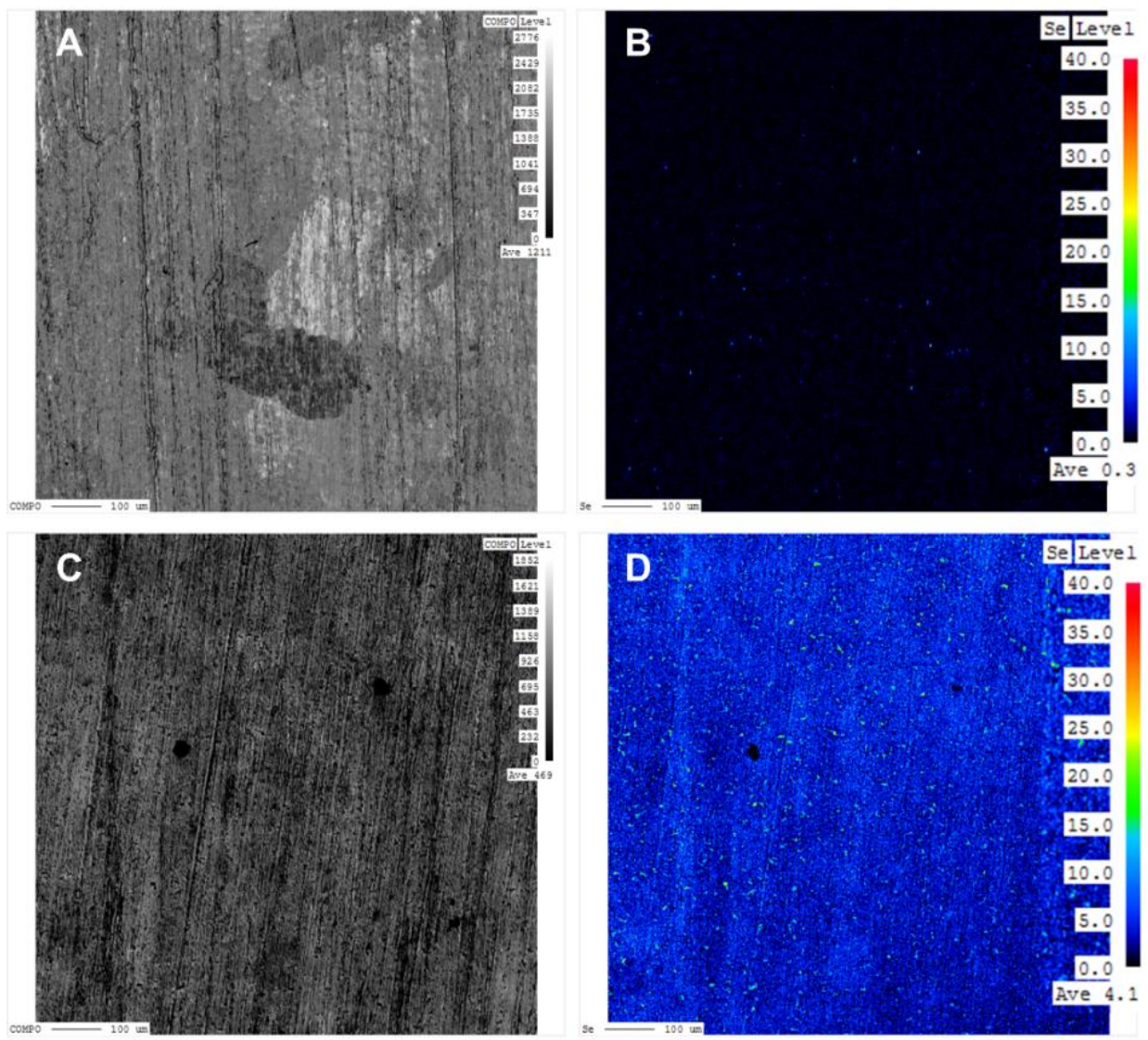

Figure S2. (A) Surface morphology and (B) elemental mapping of the Se-deposited gold electrode under the bulk deposition of a four-electron pathway. (C) Surface morphology and (D) elemental mapping of the Se-deposited gold electrode under a sixelectron pathway. 


\section{SeDER via a six-electron pathway}

Parts of the chemically precipitated $\operatorname{Se}(0)$ would attach to the Au electrode surface. The rest $\operatorname{Se}(0)$ were either suspended in the solution or settled at the bottom of the cell.

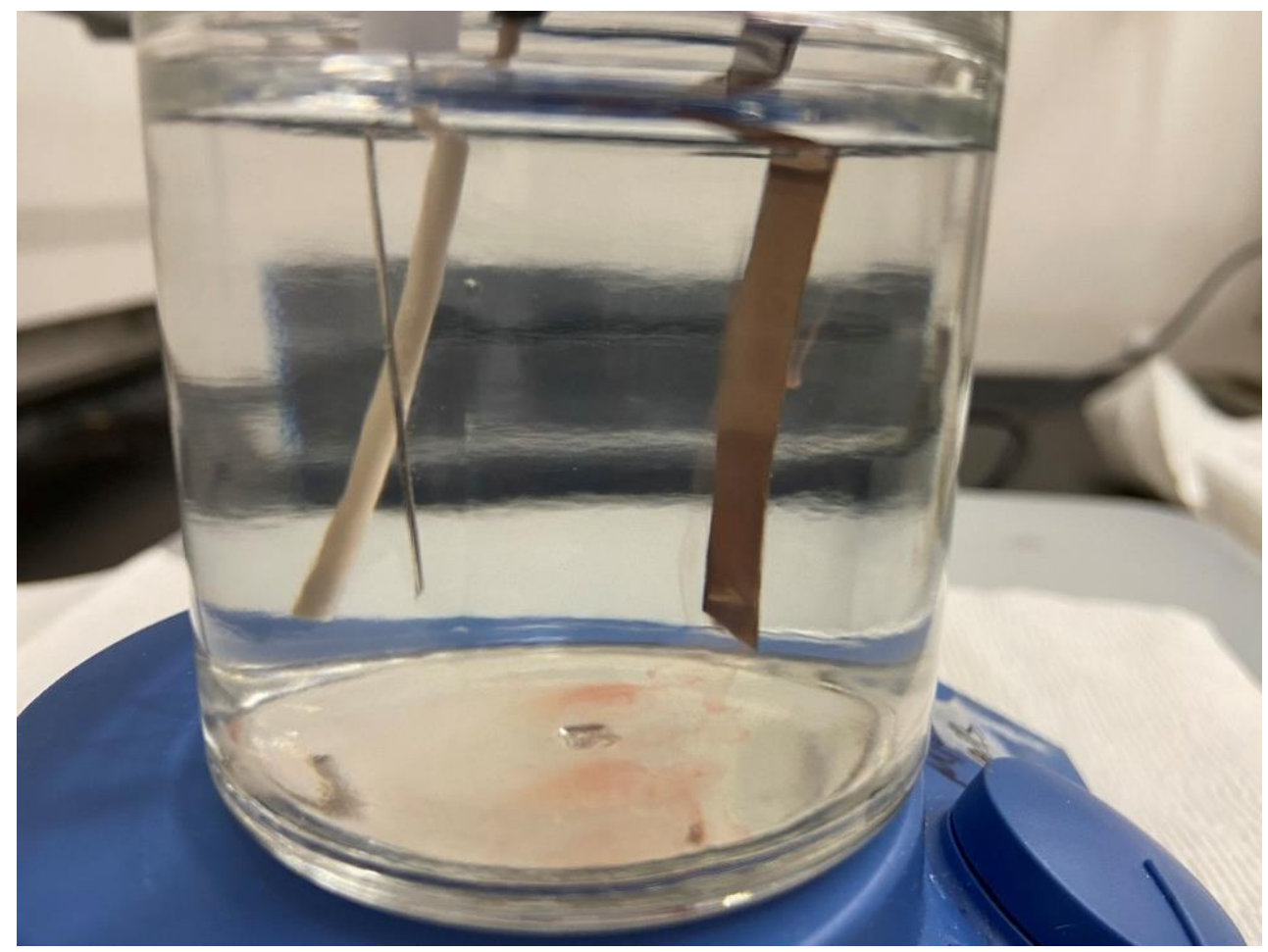

Figure S3. Setup of the three-electrode electrochemical system for room temperature operation (left) and high-temperature operation (right).

\section{Effect of temperature on SeDER}

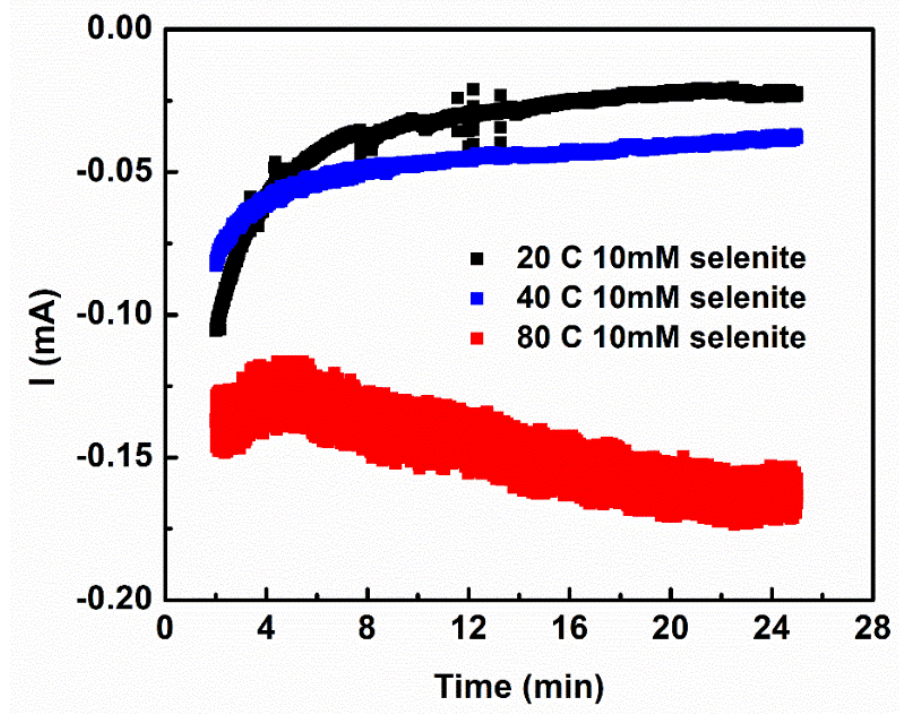

Figure S4. The current profile of CA under different solution temperatures. 


\section{Long-term Se reduction experiments}
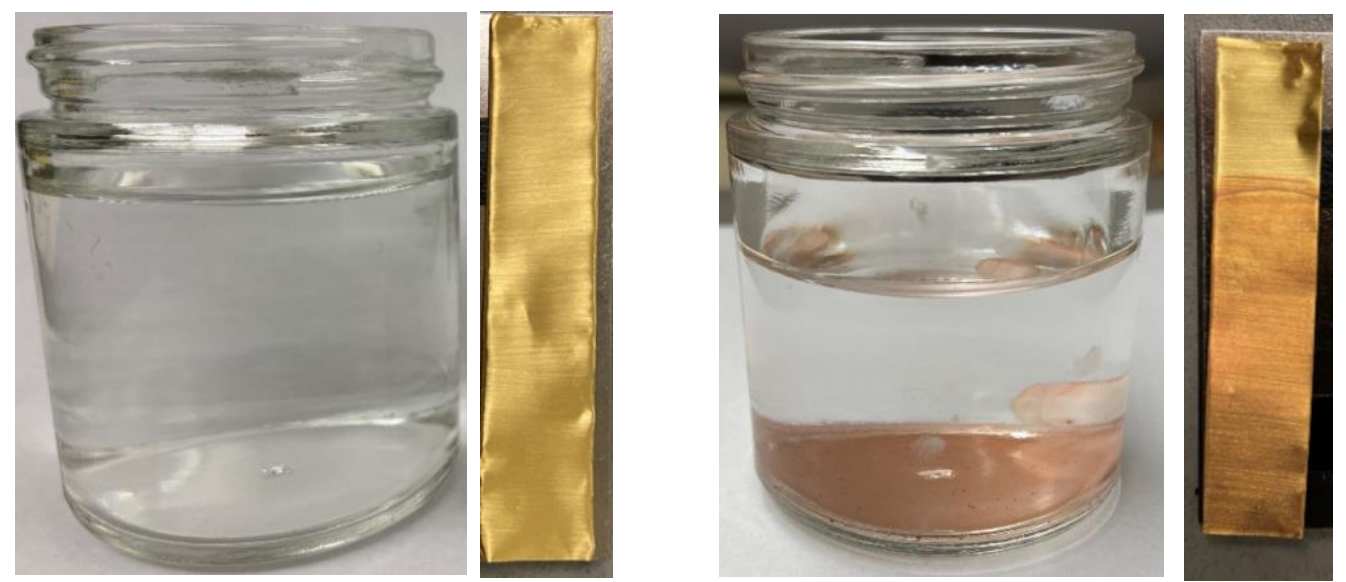

Figure S5. SeDER under 20 and $40{ }^{\circ} \mathrm{C}$ via the four-electron pathway (left) and the sixelectron pathway (right).
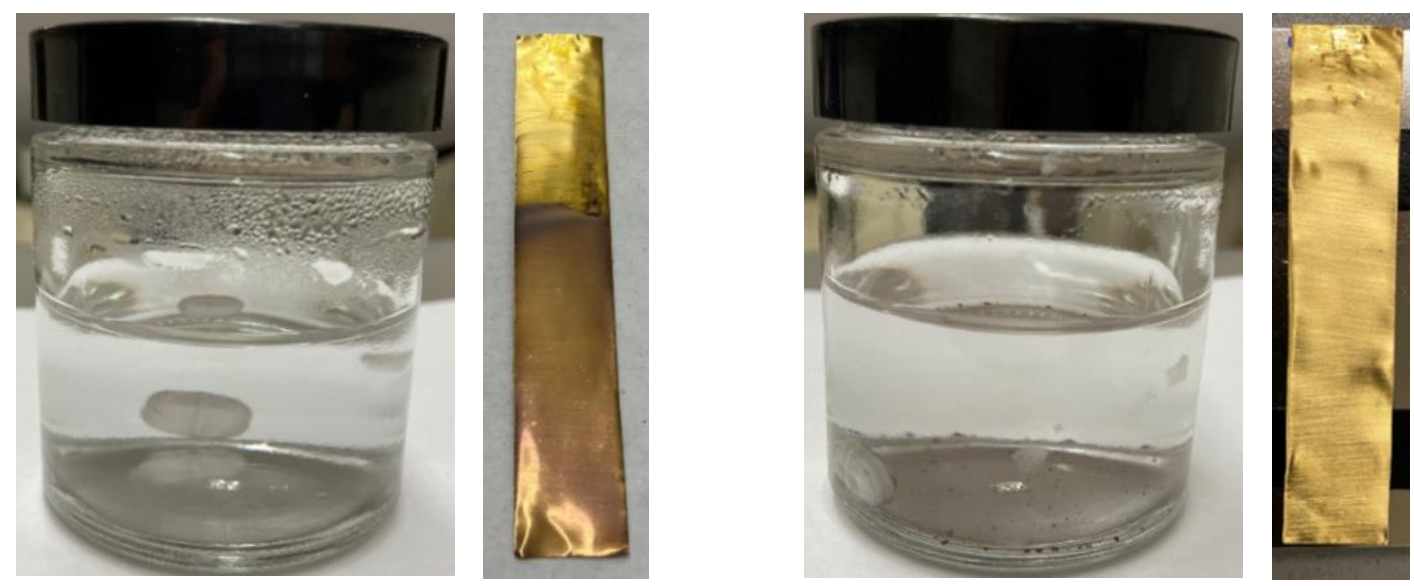

Figure S6. SeDER under high temperature $\left(80^{\circ} \mathrm{C}\right)$ via the four-electron pathway (left) and the six-electron pathway (right). Most of the generated grey $\operatorname{Se}(0)$ were settled at the bottom of the reactor in the six-electron pathway, and the rest $\operatorname{Se}(0)$ were attached to the Au electrode (not very obvious due to the metallic color).

\section{Calculation for $\mathrm{pH}$ correction of the potential}

Assuming 1-M $\mathrm{HSeO}^{3-}$ is available in the solution, a $\mathrm{pH}$ increase from 0 (standard condition) to 5.5 would drop the reduction potential from $0.58 \mathrm{~V}$ to $0.21 \mathrm{~V}(273 \mathrm{~K})$.

$$
\mathrm{E}=\mathrm{E}^{\circ}-\frac{\mathrm{RT}}{\mathrm{nF}} \ln \frac{1}{\left[\mathrm{HSeO}_{3}^{-}\right]\left[\mathrm{H}^{+}\right]^{5}}=0.58-\frac{8.314 \times 273}{4 \times 96485} \ln \frac{1}{1 \times\left(10^{-5.5}\right)^{5}}=0.21 \mathrm{~V}
$$




\section{Kinetic analysis of SeDER}

For the four-electron pathway, a negative shift of the cathodic peak with increasing scan rate is observed (Fig. S7), suggesting this four-electron pathway is a quasi-reversible reaction. We can also find a linear relationship between peak current density $\left(\mathrm{j}_{\mathrm{p}}\right)$ and square root of scan rate $\left(\mathrm{v}^{1 / 2}\right)$. This suggests the $\mathrm{Se}(\mathrm{IV}) / \mathrm{Se}(0)$ is most likely a process limited by mass transport. Based on our linear fitting, we get

$$
j_{p}=0.4958\left(\frac{F^{3}}{R T}\right)^{1 / 2} \alpha^{1 / 2} n^{3 / 2} D^{1 / 2} C v^{1 / 2}=3.01 \times 10^{5} \times \alpha^{1 / 2} n^{3 / 2} D^{1 / 2} C v^{1 / 2}
$$

where $\alpha$ transfer coefficient

n \# of electrons transferred (4)

D diffusion coefficient

C concentration $(0.0001 \mathrm{M})$

$\mathrm{v}$ scan rate

We then plot Tafel dependence between overpotential $(\eta)$ and $\log _{10 j}$ (Fig. S7). We use overpotential range of $-50 \mathrm{mV}$ to $-150 \mathrm{mV}$ for linear fitting and get the follow equation under a scan rate of $50 \mathrm{mV} \mathrm{s}^{-1}$ :

$\mathrm{y}=-0.0060 \mathrm{x}-4.9131\left(\mathrm{R}^{2}=0.9980\right.$, scan rate $\left.=50 \mathrm{mV} \mathrm{s}^{-1}\right)$

The Tafel slope

$$
\text { slope }=-0.0060=\frac{-\alpha F}{2.3 R T}
$$

Hence, we have the transfer coefficient $\alpha=0.10$.

The Tafel intercept is

$$
\text { intercept }=\log _{10} j_{0}=-4.9131
$$

We have exchange current density $\mathrm{j}_{\mathrm{o}}=1.22 \times 10^{-5} \mathrm{~A} \mathrm{~cm}^{-2}$.

The standard rate constant, $\mathrm{k}_{\mathrm{o}}$ can be quantified via

$$
j_{o}=n F k_{o} C=1.22 \times 10^{-5}
$$

Hence, we have standard rate constant $\mathrm{k}_{0}=3.16 \times 10^{-7} \mathrm{~cm} \mathrm{~s}^{-1}$ ( $\underline{\text { slow reaction }}$ ).

Finally, the diffusion coefficient can be calculated by

$$
0.6343=3.01 \times 10^{5} \times \alpha^{1 / 2} n^{3 / 2} D^{1 / 2} C
$$

We get the $\mathrm{Se}^{4+}$ diffusion coefficient $\mathrm{D}=6.94 \times 10^{-5} \mathrm{~cm}^{2} \mathrm{~s}^{-1}$. 

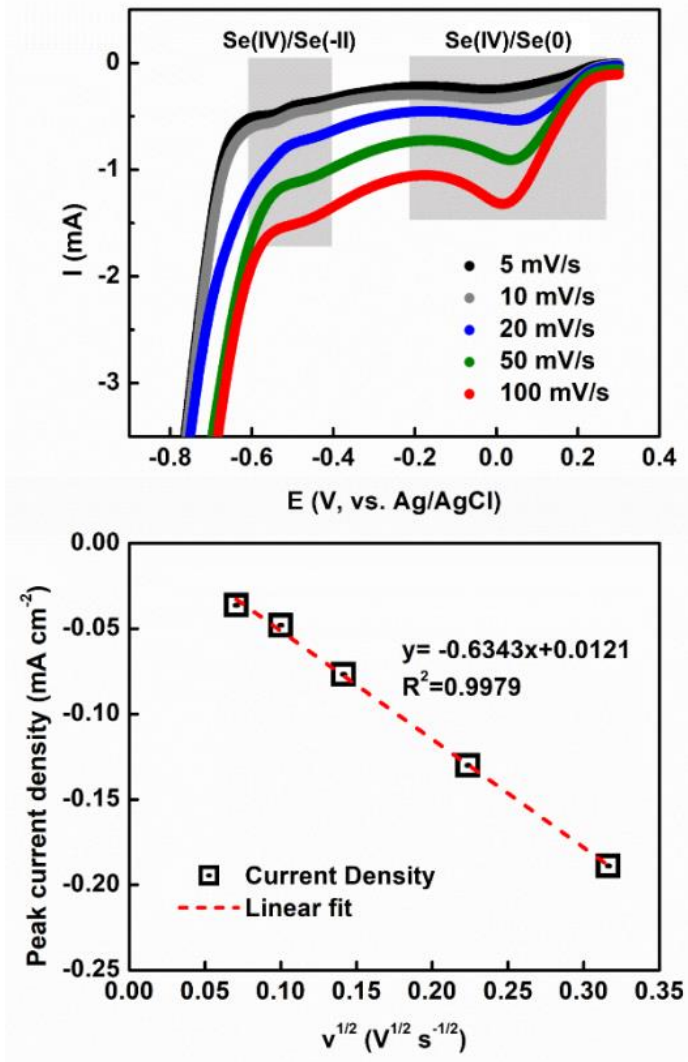

Figure S7. Kinetic analysis of SeDER under a series of LSV scan rates. The top figure describes the current profile of LSV under various scan rates, while the bottom figure plots the square root of the scan rate versus the peak current density for $\mathrm{Se}(\mathrm{IV}) / \mathrm{Se}(0)$ reaction.

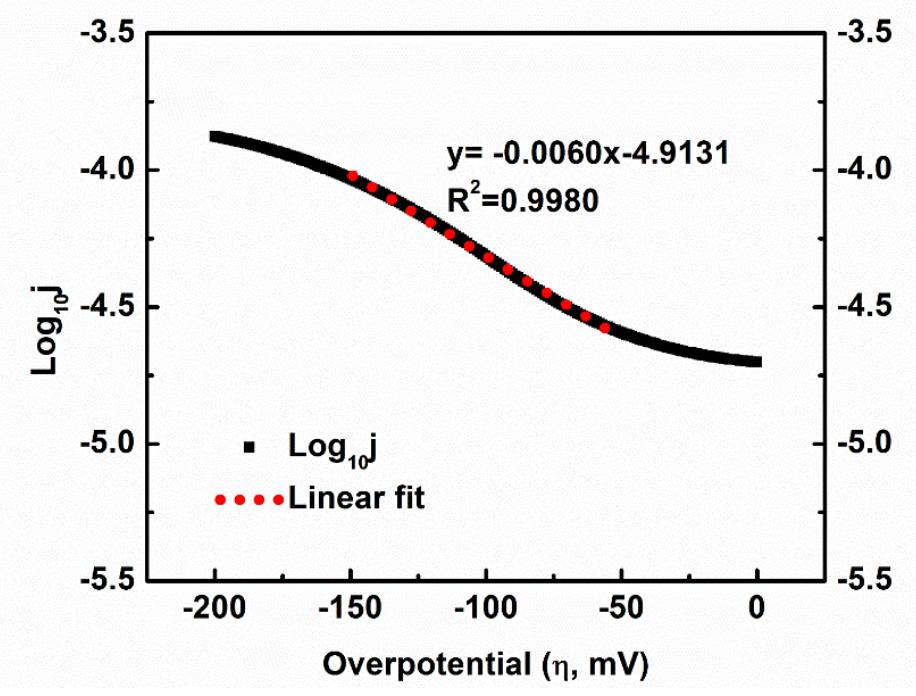

Figure S8. Tafel plot between overpotential $(\eta)$ and $\log _{10 j}$. The data come from the LSV scan rate of $50 \mathrm{mV} \mathrm{s}^{-1}$. 


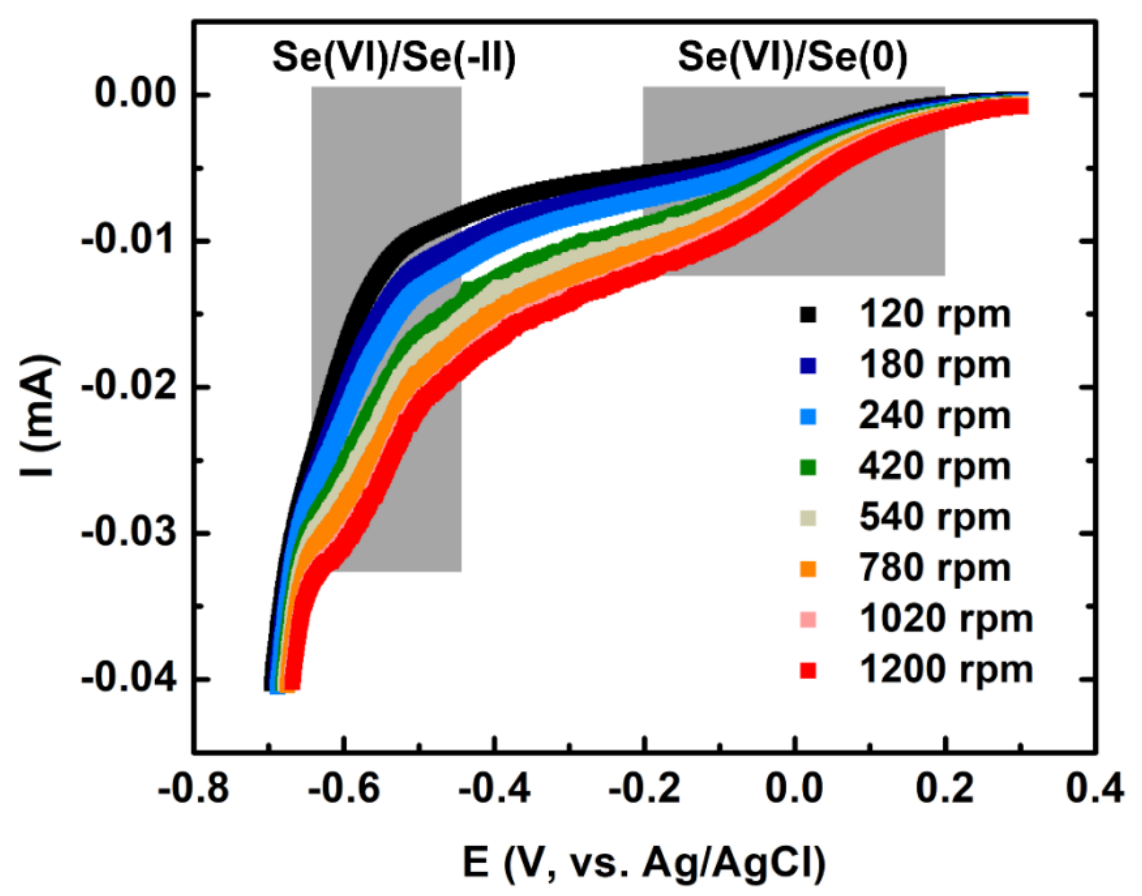

Figure S9. Kinetic analysis of SeDER under a series of rotating speeds using a rotating disk electrode $(\mathrm{Au})$. Both four- and six-electron pathway peaks cannot be clearly identified for an accurate kinetic analysis.

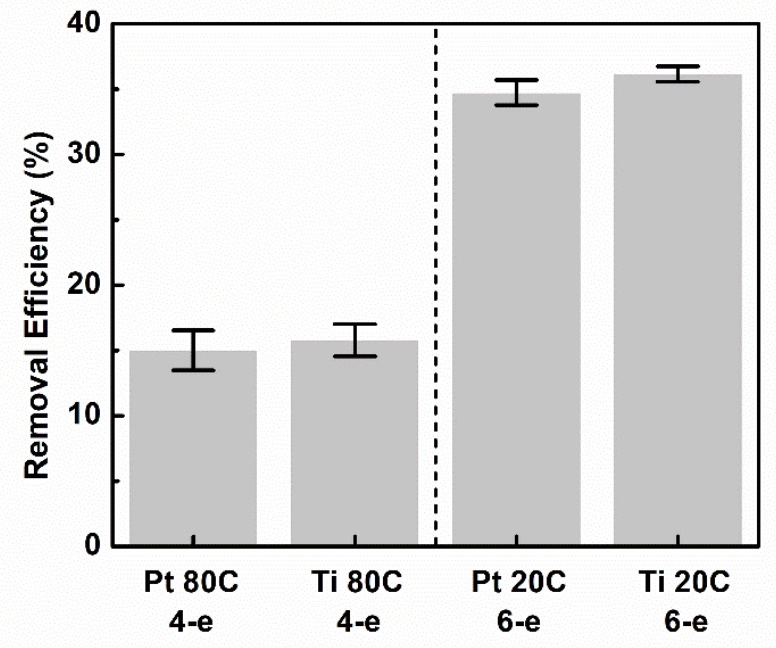

Figure S10. Se removal efficiencies using either a Pt wire or a Ti foil electrode in fourelectron and six-electron Se reduction pathways in a 6-hour operation. Gradual oxidation of $\mathrm{Ti}$ to $\mathrm{TiO}_{2}$ was observed beyond a 6-hour operation. 


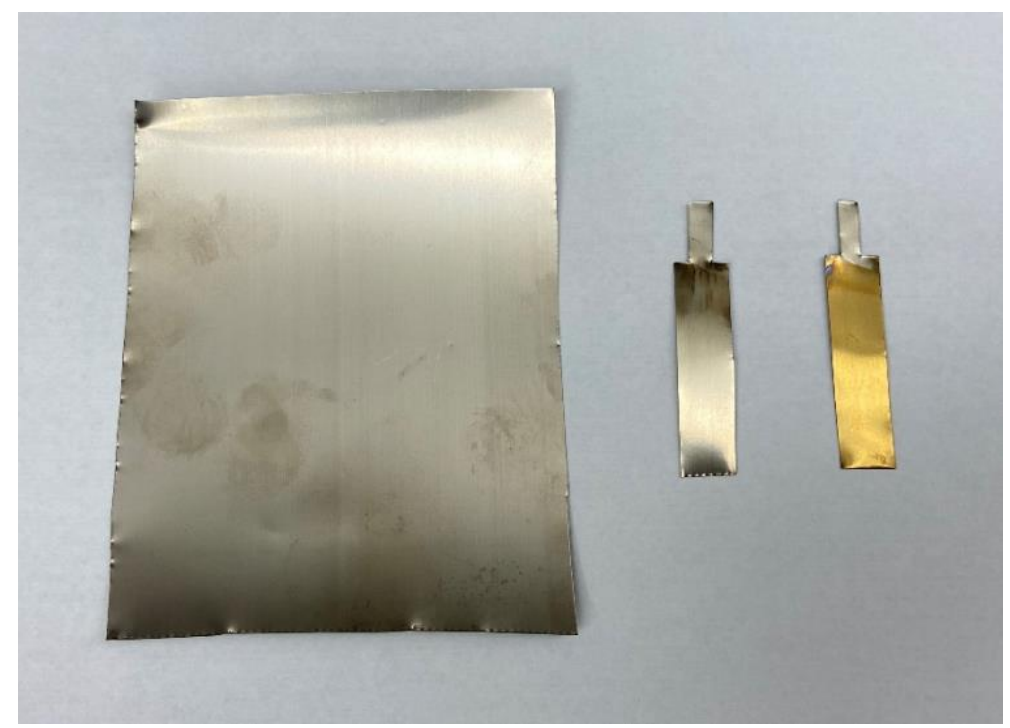

Figure S11. Ti bulk foil, Ti counter electrode in a 6-h operation, and Ti counter electrode in a 24-h operation (from left to right). Gradual oxidation of Ti results in a surface color change. 